\title{
Sistem Pengelolaan Limbah Plastik di Kota Lhokseumawe - Provinsi Aceh
}

\author{
Syaifuddin Yana ${ }^{1 *}$, Dewi Mulyati ${ }^{2}$, Badaruddin $^{3}$, Halimatussakdiah $^{4}$ \\ 1,2Program Studi Teknik Industri, Fakultas Teknik, Universitas Serambi Mekkah \\ ${ }^{3}$ Program Studi Manajemen, Fakultas Ekonomi, Universitas Serambi Mekkah \\ ${ }^{4}$ Program Studi Manajemen, Fakultas Ekonomi, Universitas Syiah Kuala \\ *Koresponden email: syaifuddin.yana@serambimekkah.ac.id
}

Diterima : 28 Desember 2018

Disetujui: 2 Februari 2019

\begin{abstract}
The study aims to describe the plastic waste management from a processing perspective that has economic value added. Conversion of waste into an economic value, is one practice that can be a role of model, so that it can guide a certain region to do good and correct waste of management. The potential of Aceh's plastic waste is relatively large, which must be considered by the regional government to be able to realize related to plastic waste processing activities by the processor, where the existence is a large potential to be used as an opportunity for recycle. The current practice is still a little and only processing the plastic waste to become plastic chips, and there is no plastic waste processing converted into processed plastic products. The existence of this processing can provide economic added value for its owners and provide benefits to local governments as well. Therefore, it is need the role of the Aceh government to bring up the spirit of entrepreneurship, especially in the management and processing of plastic waste. On the other hand, a spirit of togetherness is needed through coordination and cooperation between local governments and non-governmental institutions, activists and environmentalists to carry out the mandate of the law relating to environmental conservation including waste management activities that can be added to economic value.
\end{abstract}

Keywords: plastic waste treatment, economic value added, cleanliness and environmental preservation entrepreneurial spirit

\begin{abstract}
Abstrak
Kajian literatur ini bertujuan untuk memaparkan pengelolaan limbah plastik dari perspektif pengolahan yang menjadi nilai tambah ekonomi. Konversi sampah menjadi suatu yang bernilai ekonomi, merupakan salah satu praktek yang dapat menjadi contoh model agar dapat menjadi panduan suatu daerah untuk melakukan pengelolaan sampah yang baik dan benar. Potensi limbah plastik Aceh relatif besar, yang harus menjadi pertimbangan pemerintah daerah untuk dapat merealisasikan terkait kegiatan pengolahan limbah plastik oleh penggiat pengolahan limbah plastik, dimana keberadaannya merupakan potensi besar untuk dijadikan peluang untuk dijadikan pengolahan limbah plastik (recycle). Praktek yang dilakukan saat ini yaitu masih sedikit dan hanya mengolah limbah plastik untuk menjadi plastik cacah (chips plastic), dan belum ada lagi pengolahan limbah plastik (plastic recycle) dikoversi menjadi produk olahan plastik jadi. Keberadaan pengolahan ini dapat memberikan nilai tambah ekonomi bagi pengelolanya dan memberikan keuntungan bagi pemerintah daerah. Perlunya peran pemerintah daerah Aceh untuk memunculkan semangat entrepreneurship khususnya dalam pengelolaan dan pengolahan limbah plastik. Oleh karena itu, diperlukan semangat kebersamaan melalui koordinasi dan kerjasama antar pemerintah daerah dengan lembaga non pemerintah, penggiat dan pemerhati lingkungan untuk menjalankan amanat undang-undang terkait pelestarian lingkungan termasuk kegiatan pengolahan limbah menjadi bernilai tambah ekonomi dapat terwujud.
\end{abstract}

Kata Kunci: Pengolahan limbah plastik, nilai tambah ekonomi, kebersihan dan pelestarian lingkungan. semangat entrepreneurship

\section{Pendahuluan}

Undang-Undang Republik Indonesia Nomor 23 Tahun 1997, tentang pengelolaan lingkungan hidup; Bab III Hak, Kewajiban, Dan Peran Masyarakat; Pasal 6.1: Setiap orang berkewajiban memelihara kelestarian fungsi lingkungan hidup serta mencegah dan menanggulangi pencemaran dan perusakan lingkungan hidup. Selanjutnya Pasal 7.1: Masyarakat mempunyai kesempatan yang sama dan seluas luasnya untuk berperan dalam pengelolaan lingkungan hidup. Berdasarkan Undang-undang tertera di atas jelas bahwa baik individu maupun masyarakat, wajib untuk menjaga kelestarian lingkungan hidup yang apabila diabaikan akan berdampak luas kepada lingkungan dan masyarakat. Oleh karenanya, perlu perhatian bersama dalam menjaga dan memelihara lingkungan kita. Pelestarian lingkungan 


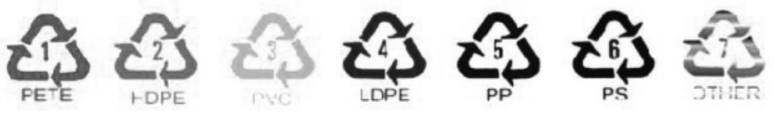

Gambar 1: Klasifikasi plastik berdasarkan penomorannya

hidup, perlu menjadi perhatian seluruh elemen baik pemerintah, masyarakat, pelaku/penggiat dan pemerhati lingkungan dan pihak yang berkepentingan lainnya. Pelestarian lingkungan umumnya juga dikaitkan dengan bagaimana melakukan penanganan, penanggulangan termasuk menjaga kebersihan lingkungan dan penganggulangan sampah yang berada di lingkungan masyarakat serta bagaimana pengelolaan sampah itu sebaiknya dilakukan.

Undang-undang Republik Indonesia no. 32 tahun 2009, tentang perlindungan dan pengelolaan lingkungan hidup. Bab I pasal 1 No. 3: Pembangunan berkelanjutan adalah upaya sadar dan terencana yang memadukan aspek lingkungan hidup, sosial, dan ekonomi ke dalam strategi pembangunan untuk menjamin keutuhan lingkungan hidup serta keselamatan, kemampuan, kesejahteraan, dan mutu hidup generasi masa kini dan generasi masa depan; No. 33: Instrumen ekonomi lingkungan hidup adalah seperangkat kebijakan ekonomi untuk mendorong pemerintah, pemerintah daerah, atau setiap orang ke arah pelestarian fungsi lingkungan hidup. Berdasarkan undang-undang no. 32, jelas bahwa pengelolaan sampah pada umumnya dan juga termasuk sampah plastik perlu dikelola dengan benar. Tentu saja, aspek pengelolaan sampah ini tidak dapat dilakukan dalam skala kecil dan terputus-putus dalam jangka pendek.

Pengelolaan sampah plastik ini merupakan bagian yang tidak dapat dipisahkan pada pembangunan berkelanjutan dan merupakan bagian dari aspek pelestarian lingkungan hidup, sosial dan lebih jauh lagi aspek pembangunan ekonomi yang berkelanjutan. Dari no. 33, pemerintah juga berkewajiban untuk mendorong praktik-praktik pelestarian lingkungan hidup dan menjadi motor yang dapat menumbuhkan semangat masyarakat, pelaku dan penggiat pengelolaan sampah plastik, sehingga kegiatan ini menjadi unsur yang memberikan nilai tambah ekonomi dan sekagus menjadi bagian dari pelestarian lingkungan hidup.

Undang-Undang Republik Indonesia No. 18 tahun 2008 tentang Pengolahan Sampah; Bab II Asas dan Tujuan; pasal 3 berbunyi: Pengelolaan sampah diselenggarakan berdasarkan asas tanggung jawab, asas berkelanjutan, asas manfaat, asas keadilan, asas kesadaran, asas kebersamaan, asas keselamatan, asas keamanan, dan asas nilai ekonomi. Pasal 4 berbunyi: Pengelolaan sampah bertujuan untuk meningkatkan kesehatan masyarakat dan kualitas lingkungan serta menjadikan sampah sebagai sumber daya. Berdasarkan undang-undang tersebut, menjadi penting bagaimana sebaiknya sampah diperlakukan, baik dari perspektif tanggung jawab sampai dengan bagaimana sampah itu dapat menjadi nilai tambah ekonomi. Konversi sampah menjadi suatu yang bernilai ekonomi, masih sangat jarang didengungkan khususnya di Aceh. Setidaknya, jarang sekali dalam prakteknya bagaimana praktis pengelolaan sampah ini sebaiknya diperlakukan. Sedikit sekali praktekpraktek yang dapat dijadikan contoh model agar dapat menjadi panduan suatu daerah agar dapat melakukan pengelolaan sampah yang baik dan benar.

Berdasarkan paparan dari Ditjen Pengelolaan Sampah, Limbah, dan B3 KLHK total jumlah sampah Indonesia di 2019 akan mencapai 68 juta ton. Sampah plastik diperkirakan akan mencapai 9,52 juta ton atau 14 persen dari total sampah yang ada. Padahal, KLHK menargetkan pengurangan sampah plastik lebih dari 1,9 juta ton hingga 2019. Sampah plastik merupakan salah satu permasalahan terbesar bagi masyarakat, karena jumlah sampah tersebut menempati peringkat pertama dari volume sampah yang ada. Pengelolaan sampah plastik memerlukan penanganan khusus dengan metode yang tepat dan dilakukan secara komprehensif dari hulu ke hilir. Jika tidak dikelola secara tepat sampah plastik akan berdampak buruk terhadap lingkungan karena sukar terurai secara cepat dan alami. Menurut Katz (1995), limbah plastik dapat terdegradasi di lingkungan dalam kurun waktu 450 hingga 600 tahun. Meningkatnya jumlah sampah plastik setiap tahun tidak diimbangi dengan pengelolaan yang benar, mengakibatkan jumlah sampah yang bertumpuk. Sampah plastik jika dibakar menyebabkan pencemaran udara, jika ditimbun merusak struktur tanah. Jika sampah plastik, penanganannya tidak dilakukan dengan metoda yang tepat akan berakibat jumlah sampah yang tidak terkendali dan pencemaran lingkungan.

Pada prakteknya di Aceh, sampah plastik hanya sedikit sekali jumlahnya yang diolah melalui daur ulang. Pengolahan sampah plastik yang banyak dilakukan oleh masyarakat dengan cara membakar secara langsung. Apabila kegiatan pembakaran dilakukan secara tidak sempurna di bawah temperatur $800^{\circ} \mathrm{C}$, akan membentuk senyawa dioksin yang bersifat toksik (Vedder, T. 2008). Untuk jenis plastik tertenu seperti plastik biodegradable, menurut Seal dan Griffin (1994), plastik biodegradable merupakan suatu bahan dalam kondisi tertentu, waktu tertentu mengalami perubahan dalam struktur kimianya, yang mempengaruhi sifat-sifat yang dimilikinya karena pengaruh mikroorganisme (bakteri, jamur, alga). Plastik biodegradable yang terbakar tidak berbahaya karena tidak menghasilkan senyawa kimia yang berbahaya. 


\begin{tabular}{cl}
\hline No. & Jenis Plastik \\
\hline 1 & $\begin{array}{l}\text { PET } \\
\text { (Polyethylene } \\
\text { Terephthalate) }\end{array}$ \\
& \\
2 & HDPE (High \\
& $\begin{array}{l}\text { Density } \\
\text { Polyethylene) }\end{array}$
\end{tabular}

Ciri/Bentuk, Sifat dan Produk Bagian bawah kemasan botol plastik, tertera logo daur ulang dengan angka 1 di tengahnya dan tulisan PETE atau PET (polyethylene terephthalate) di bawah segitiga. Dalam industri tekstil PET biasa disebut dengan polyester. Biasa dipakai untuk botol plastik yang jernih/ transparan/tembus pandang seperti botol air mineral, botol jus, dan hampir semua botol minuman lainnya. 2 di tengahnya, serta tulisan HDPE segitiga. Umumnya dipakai untuk botol susu yang berwarna putih susu, galon air minum, dan lain-lain. HDPE merupakan salah satu bahan plastik yang aman untuk digunakan karena kemampuan untuk mencegah reaksi kimia antara kemasan plastik berbahan HDPE dengan makanan/minuman yang dikemasnya. HDPE memiliki sifat bahan yang lebih kuat, keras hingga semifleksibel, buram dan lebih tahan terhadap bahan kimia dan kelembapan, melunak pada suhu $750^{\circ}$ Celcius.

3 PVC (Polyvinyl Terdapat logo daur ulang (terkadang Chloride) berwarna merah) dengan angka 3 di tengahnya, serta tulisan $\mathrm{V}-\mathrm{V}$ itu berarti PVC (polyvinyl chloride), yaitu jenis plastik yang paling sulit didaur ulang. Plastik ini bisa ditemukan pada plastik pembungkus (cling wrap), dan botolbotol, sulit di daur ulang. PVC mengandung DEHA yang dapat bereaksi dengan makanan yang dikemas dengan plastik berbahan PVC ini saat bersentuhan langsung dengan makanan tersebut karena DEHA lumer pada suhu $150^{\circ}$ Celcius. Reaksi yang terjadi antara PVC dengan makanan yang dikemas dengan plastik ini berpotensi berbahaya untuk ginjal, hati dan berat badan. Plastik jenis ini sebaiknya tidak untuk mewadahi pangan yang mengandung lemak/minyak, alkohol dan dalam kondisi panas.

4 LDPE (Low Terdapat logo daur ulang dengan angka Density 4 di tengahnya, serta tulisan LDPE (low Polyethylene) density polyethylene) dimana plastik tipe cokelat (thermoplastic/dibuat dari minyak bumi), biasa dipakai untuk tempat makanan, plastik kemasan, dan botol-botol yang lembek. Sifat mekanis jenis plastik LDPE adalah kuat, fleksibel, kedap air tetapi tembus cahaya, fleksibel dan permukaan agak berlemak. Melunak pada suhu $700^{\circ} \mathrm{C}$ LDPE ini sulit dihancurkan, tetapi tetap baik untuk tempat makanan karena sulit bereaksi secara kimiawi dengan makanan yang dikemas dengan bahan ini.

5 PP Terdapat logo daur ulang dengan angka

(Polypropylene) 5 di tengahnya, serta tulisan PP PP (polypropylene) merupakan bahan terbaik untuk plastik, terutama terkait dengan makanan dan minuman seperti tempat menyimpan makanan, botol minum dan terpenting botol minum untuk bayi. Karakteristik adalah biasa botol transparan yang tidak jernih atau berawan, keras tetapi fleksibel. Polipropilen lebih kuat dan ringan dengan daya tembus uap yang rendah, ketahanan yang baik terhadap lemak, minyak, stabil terhadap suhu tinggi dan cukup mengkilap. Melunak pada suhu 1500 derajat Celcius.

6 PS Terdapat logo daur ulang dengan angka (Polystyrene) 6 di tengahnya, serta tulisan PS PS (polystyrene). Terdapat dua macam PS, yaitu yang kaku dan lunak/berbentuk foam. PS yang kaku biasanya jernih seperti kaca, kaku, getas, mudah terpengaruh lemak dan pelarut (seperti alkohol), mudah dibentuk, melunak pada suhu 950C. Contoh: wadah plastik bening berbentuk kotak untuk wadah makanan. PS yang lunak berbentuk seperti busa, biasanya berwarna putih, lunak, mudah terpengaruh lemak dan pelarut lain (seperti alkohol). Bahan ini dapat melepaskan styrene jika kontak dengan pangan. Contohnya yang sudah sangat terkenal styrofoam. Banyak digunakan untuk wadah makanan atau minuman sekali pakai. Bahan ini harus dihindari, karena selain berbahaya untuk kesehatan otak, mengganggu hormon estrogen pada wanita yang berakibat pada masalah reproduksi, dan pertumbuhan dan sistem syaraf, juga karena bahan ini sulit didaur ulang. Bila didaur ulang, bahan ini memerlukan proses yang sangat panjang dan lama.

7 Others Terdapat logo daur ulang dengan angka 7 di tengahnya, serta tulisan OTHER Other SAN (styrene acrylonitrile), ABS (acrylonitrile butadiene styrene), PC (polycarbonate, Nylon). Umumnya ditemukan pada tempat makanan dan minuman seperti botol minum olahraga, alat-alat rumah tangga, peralatan makan bayi dan plastik kemasan. PC (Polycarbonate) dapat ditemukan pada botol susu bayi, gelas anak batita (sippy cup). Dapat mengeluarkan bahan utamanya yaitu Bisphenol-A ke dalam makanan dan minuman yang berpotensi merusak sistem hormon, kromosom pada ovarium, penurunan produksi sperma, dan mengubah fungsi imunitas. Dianjurkan untuk tidak dipergunakan untuk tempat makanan ataupun minuman karena Bisphenol-A dapat berpindah ke dalam minuman atau makanan jika suhunya dinaikkan karena pemanasan. Untuk mensterilkan botol susu, sebaiknya direndam saja dalam air mendidih dan tidak direbus

Sumber: Koswara (2006)

Jika ditimbun dapat menyebabkan kualitas tanah dapat meningkat karena hasil penguraian mikroorganisme meningkatkan unsur hara dalam tanah. Jika dibandingkan plastik biasa membutuhkan waktu dapat lebih dari 50 tahun agar dapat terdekomposisi oleh alam, sebaliknya plastik biodegradable dapat terdekomposisi lebih cepat yaitu 10 hingga 20 kali lebih cepat. Plastik biodegradable memiliki beberapa keunggulan dibandingkan plastik sintetis. Selain sifatnya yang mudah terurai, lebih 


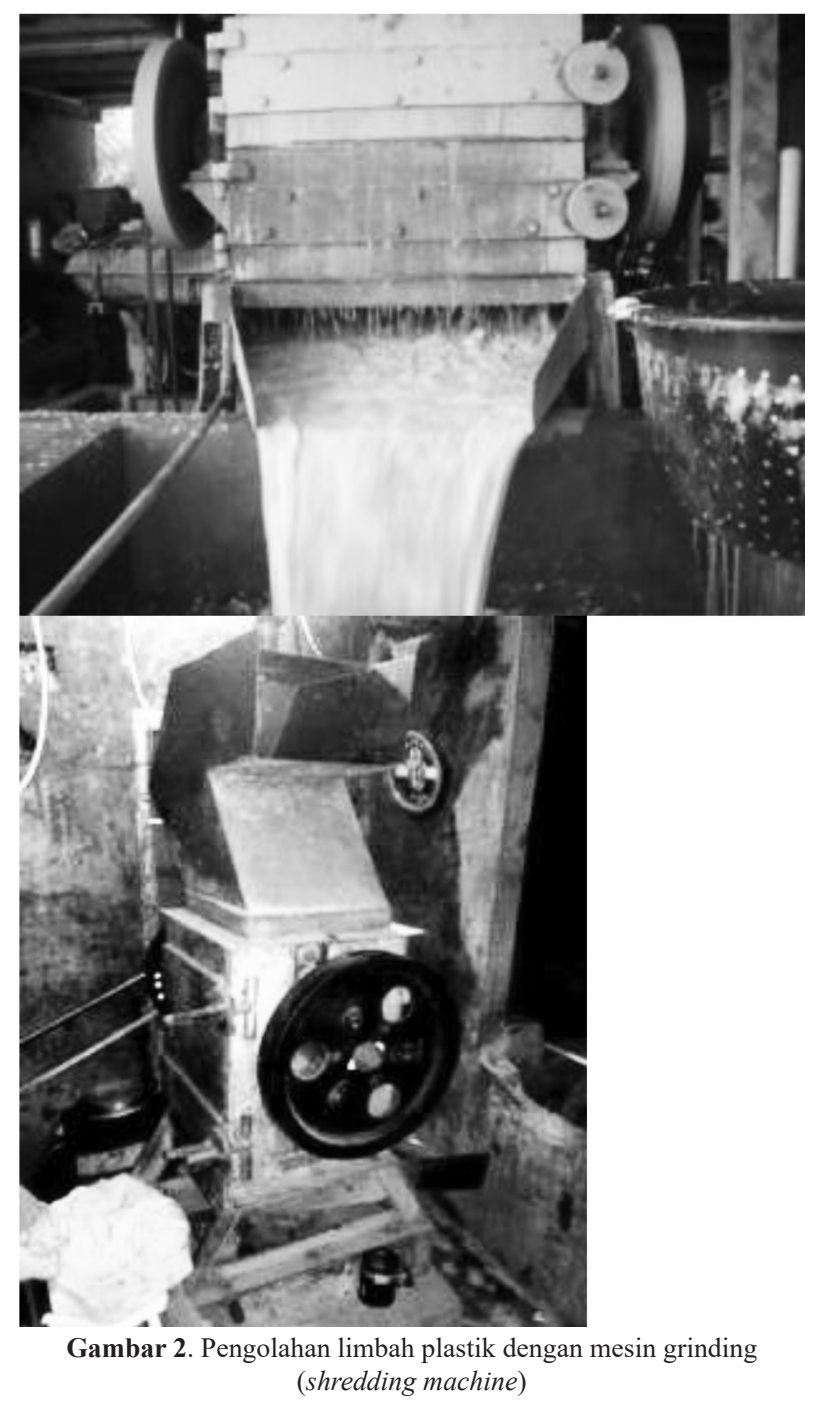

aman digunakan sebagai kemasan makanan dan proses pembuatannya menghasilkan emisi karbon yang lebih kecil dibandingkan proses pembuatan plastik sintesis, (Kusumastuti, dkk, 2010). Plastik biodegradable dapat dibuat dari berbagai macam bahan alami seperti limbah kulit buah-buahan dan limbah chitosan.

Jadi jelas bahwa plastik non biodegradeble sewajarnya harus dikelola dengan seksama seperti mendaur ulang baik menjadi plastik cacah (plastik chips), biji plastik ataupun lebih jauh dapat dijadikan produk yang berbahan plastik daur ulang. Praktik tersebut menjadi salah satu kegiatan yang ramah lingkungan.

\section{Tinjauan Pustaka}

\subsection{Klasifikasi Sampah}

Sampah adalah limbah yang bersifat padat terdiri atas zat organik dan zat anorganik yang dianggap tidak berguna lagi dan harus dikelola agar tidak membahayakan lingkungan dan melindungi investasi pembangunan, (Literatur). SNI 19-2425 tahun 1991 menjelaskan bahwa sampah umumnya berupa sisa makanan (sampah dapur), daun-daunan, ranting pohon, kertas/karton, plastik, kain bekas, kalengkaleng, dan debu sisa penyapuan.

Sampah dapat diklasifikasikan dari segi sifat, jenis dan proses terjadinya, (Sahnung, 2000).

1. Berdasarkan sifatnya, sampah diklasifikasikan menjadi sampah organik dan anorganik.

2. Berdasarkan jenisnya, sampah diklasifikasikan menjadi 9 (sembilan) macam yaitu: (a) sampah makanan, (b) sampah kebun/pekarangan, (c) sampah keras, (d) sampah plastik, karet, dan kulit, (e) sampah kain, (f) sampah kayu, (g) sampah logam, (h) sampah gelas dan keramik, serta (i) sampah berupa abu dan debu.

3. Berdasarkan proses terjadinya sampah diklasifikasikan (Slamet, 1994), menjadi sampah berdasarkan sifat biologis dan kimianya menjadi 3 (tiga) macam, yaitu (a) sampah yang mudah terdegradasi, (b) sampah yang sulit terdegradasi dan (c) sampah industri.

\subsection{Sistem Pengelolaan Sampah}

Pengolahan sampah adalah upaya untuk mengurangi volume sampah atau merubah bentuk menjadi lebih bermanfaat, antara lain dengan cara pembakaran, pengomposan, penghancuran, pengeringan dan pendaur ulangan. Menurut Standar Nasional Indonesia, SNI T-13-1990-F pengolahan sampah yaitu:

1. Pengomposan (composting) merupakan suatu cara pengolahan sampah organik dengan memanfaatkan aktifitas bakteri untuk mengubah sampah menjadi kompos (proses pematangan);

2. Pembakaran sampah. Kegiatan pembakaran sampah harus menggunakan insenerator untuk meminimalisir dampak gangguan yang ditimbulkan;

3. Recycling merupakan teknik pengolahan sampah yang memisahkan sampah yang memiliki nilai ekonomi seperti; kertas, plastik, dan karet dari sampah untuk diolah kembali;

4. Reuse merupakan teknik pengolahan sampah yang hampir sama dengan recycling, bedanya reuse langsung digunakan tanpa ada pengolahan terlebih dahulu;

5. Reduce merupakan usaha untuk mengurangi potensi timbunan sampah.

\subsection{Jenis-Jenis dan Klasifikasi Limbah Plastik}

Menurut Koswara (2006), jenis-jenis plastik dan klasifikasinya berdasarkan proses kimianya adalah sebagai berikut.

PETE atau PET (Polyethylene Terephthalate), HDPE (High Density Polyethylene), PVC (Polyvynil Chloride), LDPE (Low Density Polyethylene), PP 
(Polypropylene), PS (Polystyrene) dan lainnya biasanya dalam bentuk polycarbonate.

\section{Metode Penelitian}

Studi ini memaparkan dan menelaah praktek terkait kegiatan pengelolaan sampah plastik yang ada di Aceh saat ini. Dalam pelaksanaannya, praktek pengelolaan sampah plastik dengan menggunakan metoda pengolahan menjadi produk berikutnya (recycle), masih sangat terbatas dan juga masih kurang mendapatkan perhatian yang serius dari pemerintahan daerah. Gambaran pengolahan limbah plastik yang terdapat di daerah Aceh, dimana pengolahan yang banyak ditemui adalah pengolahan sederhana dengan menggunakan mesin grinding sehingga dihasilkan plastik cacah, seperti terlihat pada display di bawah.

Gambar 2. merupakan pendekatan yang digunakan untuk pengelolaan limbah/sampah seperti limbah padat (plastik dan lainnya) yaitu dengan pendekatan daur ulang limbah yang memiliki nilai tambah. Diantara kegiatan pengelolaan limbah padat (non organik) seperti, Kojima dan Jain (2008), adalah gambaran bagan alir limbah konsumer dan industri yang dihasilkan di India adalah dengan menggunakan proses yang sama, yaitu setelah proses pemilahan dan pembersihan, kemudian limbah plastik melalui proses pencacahan (grinding), kemudian proses pembersihan dan pengeringan. Selanjutnya dikelompokkan, proses pencetakan dan setelah menjadi butiran-butiran di kemas dan selanjutnya dijual ke industri pengolahan produk plastik.

\section{Hasil dan Pembahasan}

4.1 Amanat undang-undang Nomor 23 Tahun 1997 Pasal 7, tentang pelestarian lingkungan hidup, perihal pelaksanaan dan prakteknya masih perlu pembenahan yang komprehensif. Perlu koordinasi dan kerjasama antar pemerintah daerah dengan lembaga non pemerintah, penggiat dan pemerhati lingkungan untuk menjalankan amanat undangundang agar praktek-praktek kegiatan praktis terkait pelestarian lingkungan termasuk kegiatan pengolahan limbah menjadi bernilai tambah ekonomi dapat terlaksana dengan baik.

4.2 Terkait undang-undang Republik Indonesia Nomor 32 Bab I pasal 1 No. 3 dan No. 33, pada realitanya bahwa kegiatan ekonomi terkait pengelolaan dan pengolahan limbah plastik masih dirasakan kurang bergeliat. Praktek-praktek pengelolaan limbah plastik hanya sampai pada tahap menjadi plastik cacah, dan jumlahnya masih terbilang sedikit. Sedangkan, pengolahan lebih lanjut seperti menjadi biji plastik (pelet) ataupun lebih maju sedikit menjadi produk plastik recycle masih belum terealisasi khususnya di Aceh. Pengolahan limbah plastik tersentralisai di Kota Banda Aceh, sedangkan di kabupaten/kota masih belum tampak geliatnya.

4.3 Sebagian besar limbah plastik mengalir ke provinsi tetangga seperti Binjai, Kota Medan dan sekitarnya. Umumnya limbah plastik ini mengalir ke sentra pengolahan limbah plastik menjadi produk jadi yang berlokasi di kawasan industri Medan (KIM) di Kota Medan. Potensi limbah plastik yang ada di Aceh, saat ini hanya terkonsentrasi menjadi pengumpulan (collecting point) dalam skala kecil, menengah dan besar.

4.4 Potensi limbah plastik yang masif ini dalam jangka panjang seandainya tidak menjadi perhatian pemerintah daerah, maka dampak yang dapat terjadi yaitu penurunan dan kurang berkembangnya semangat entrepreneur, dalam pengolahan limbah plastik yang lebih memiliki nilai tambah ekonomi lebih besar. Tentu saja kondisi tersebut, pemerintah dapat kehilangan potential opportunity dalam jangka panjang, seperti kehilangan penciptaan lapangan kerja bagi industri pengelolaan limbah plastik, penerimaan daerah melalui pajak pendapatan dan pajak penghasilan, dimana seharusnya dapat menciptakan kewirausahaan masyarakat yang dapat menghasilkan potential income.

4.5 Sebagaimana semangat undang-undang Republik Indonesia No. 18 tahun 2008 tentang Pengolahan Sampah; Bab II Asas dan Tujuan; pasal 3. Karena masih minimnya pelaksana pengolahan limbah plastik di Aceh. Produk plastik jadi dari pengolahan limbah plastik (recycle) dari sisi peluang pasar banyak sekali dibutuhkan untuk keperluan misalnya rumah tangga, pertanian, kantor dan lainnya yang masih sangat banyak dibutuhkan.

\section{Kesimpulan}

5.1 Sebagaimana jabaran dari undang-undang di atas, baik undang-undang 23 tahun 1997 pasal 7, $32 \mathrm{Bab}$ I pasal 1 No. 3 dan No. 33 tahun 2009. Pelaksanaan perlindungan dan pengelolaan lingkungan hidup. merupakan pembangunan yang berkelanjutan. Diperlukan usaha jangka panjang dalam rangka pengelolaan lingkungan hidup. Diperlukan semangat kebersamaan melalui koordinasi dan kerjasama antar pemerintah daerah dengan lembaga non pemerintah, penggiat dan pemerhati lingkungan untuk menjalankan amanat undang-undang terkait pelestarian lingkungan termasuk kegiatan pengolahan limbah menjadi bernilai tambah ekonomi dapat terlaksana dengan baik. 
5.2 Amanat undang-undang No. 18 tahun 2008, Pengelolaan sampah diselenggarakan berdasarkan asas tanggung jawab. Oleh karena itu, menjadi penting bagaimana sebaiknya sampah diperlakukan, baik dari perspektif tanggung jawab sampai dengan bagaimana sampah itu dapat menjadi nilai tambah ekonomi. Konversi sampah menjadi suatu yang bernilai ekonomi, merupakan salah satu praktek yang dapat menjadi contoh model agar dapat menjadi panduan suatu daerah agar dapat melakukan pengelolaan sampah yang baik dan benar.

5.3 Semangat yang telah diamatkan oleh undangundang, akan menjadi telaahan penting oleh pemerintah daerah Aceh untuk memunculkan semangat entrepreneurship khususnya dalam pengelolaan dan pengolahan limbah plastik, menjadi tidak hanya sampai pada plastik cacah (chips plastic), tetapi lebih jauh lagi menjadi produk olahan menjadi produk plastik jadi (recycle) yang akan menjadi nilai tambah ekonomi bagi pengelolanya dan memberikan keuntungan bagi pemerintah daerah.

5.4 Potensi limbah plastik yang ada di Aceh dengan jumlah relatif besar, yang tentunya dapat menjadi pertimbangan pemerintah daerah untuk dapat merealisasikan terkait kegiatan pengolahan limbah plastik oleh penggiat pengolahan limbah plastik, dimana keberadaannya dapat menciptakan nilai tambah ekonomi yang lebih besar dengan menciptakan dan menggiatkan entrepreneurship di bidang pengolahan limbah plastik (recycle).

5.5 Melihat potensi penggunaan produk plastik recycle tersebut pada realitanya, olahan sederhana produk limbah plastik banyak sekali dibutuhkan hampir di seluruh aspek kegiatan masyarakat seperti: produk plastik kresek, plastik polybag untuk tanaman, tali rapia dan lainnya. Potensi ini sebaiknya menjadi salah satu perhatian pemerintah daerah, agar dapat menjadi rencana kerja dan pengembangan potensi pengolahan limbah pada tahun-tahun berikutnya.

\section{Daftar Pustaka}

Katz, S., (1995). Degradation of Polymers. Materials World, 377-378.

Kojima, Michikaju and Jain, Amit (2008), Controlling Pollution in Small-scale Recycling Industries: Experiences in India and Japan.

Koswara, S., (2006). Bahaya di Balik Kemasan Plastik. e-book pangan.

Kusumastuti dkk. (2010). Plastik Biodegradable Sebagai Kemasan Makanan. Universitas Jember.
Jawa Timur.

Sahnung (2000), Implementasi Kebijakan Pemerintah Daerah Dalam Program Kebersihan Lingkungan, Tesis (tidak dipublikasikan), Program Pascasarjana Universitas Brawijaya, Malang

Seal, K.J. and Griffin, G.J.L. (1994). Test Methods and Standards for Biodegradable Plastic. Chemistry and Technology of Biodegradable Polymer. Blackie Academic and Proffesional. Chapman and Hall.

Slamet, Y. 1994. Pembangunan Masyarakat Berwawasan Partisipasi. Surakarta: Sebelas Maret University Press

Standart Nasional Indonesia Nomor SNI 19-24541991 tentang Tata Cara Pengolahan Teknik Sampah Perkotaan. Badan Standar Nasional (BSN).

Standart Nasional Indonesia Nomor SNI 19-24542002 (Revisi SNI 19-2454-1991) tentang Tata Cara Pengolahan Teknik Sampah Perkotaan. Badan Standar Nasional ( BSN).

Standart Nasional Indonesia Nomor SNI T-13-1990-F tentang Tata Cara Pengelolaan Teknik Sampah Perkotaan Badan Standarisasi Nasional

Undang-Undang Republik Indonesia Nomor 18 Tahun 2008, Tentang Pengelolaan Sampah, Bab II Asas dan Tujuan; pasal 3 dan 4.

Undang-Undang Republik Indonesia Nomor 23 Tahun 1997, Tentang Pengelolaan Lingkungan Hidup; Bab III Hak, Kewajiban, Dan Peran Masyarakat; pasal 6.1 dan 7.1.

Undang-undang Republik Indonesia no. 32 tahun 2009, Tentang Perlindungan dan Pengelolaan Lingkungan Hidup. Bab I pasal 1 No. 3 dan No. 33.

Vedder, T. (2008). Edible Film. http://japemethe. port5.com (diakses 26 Agustus 2016). 